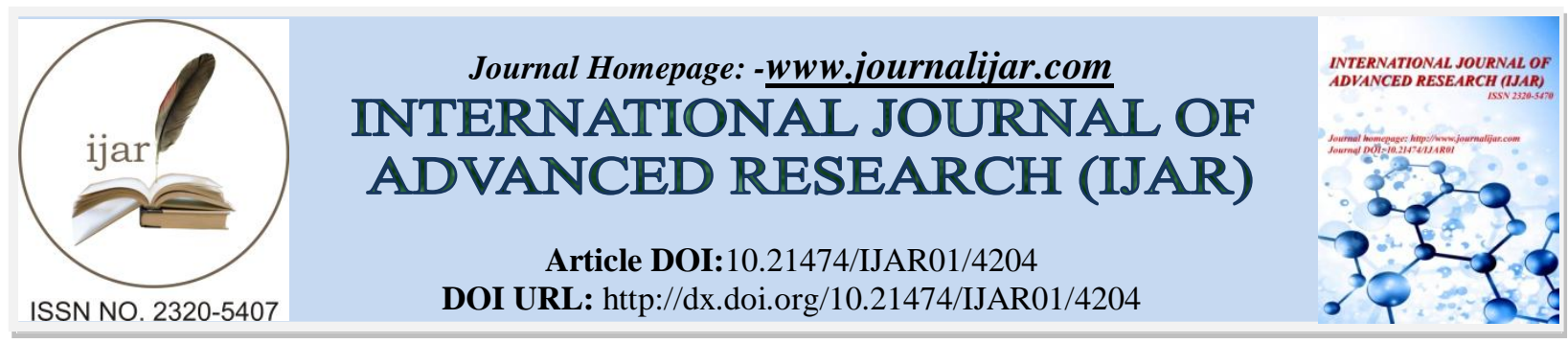

RESEARCH ARTICLE

\title{
ROLE OF ACETABULOPLASTY IN MANAGEMENT OF DEVELOPMENTAL DYSPLASIA OF THE HIP.
}

\begin{abstract}
Ahmed Mostafa El-Feky, Mohamed Anwar Abdel-Haleem, Riad Mansour Megahed, Ahmed El-Sayed ElMalt and Mahmoud El- Badawy Thabet.

Orthopedic Department in Zagazig University.
\end{abstract}

\section{Manuscript Info}

Manuscript History

Received: 15 March 2017

Final Accepted: 13 April 2017

Published: May 2017

\section{Abstract}

Background: Developmental dysplasia of the hip is a spectrum of disorder ranging from mild dysplasia up to frank dislocation.

Objectives: Evaluation of the results of Dega acetabuloplasty in cases of developmental dysplasia of the hip below 8 years.

Patients and Methods: This prospective study was conducted on thirty five hips in thirty patients of developmental dysplasia of the hip in Zagazig University hospitals, Sharqia between 2013 and 2015.

Results: Results of treatment were evaluated using clinical and radiological parameters based on modified McKay criteria and Severin classification respectively. Satisfactory results were present in thirty two hips (91.4\%), compared with unsatisfactory results in three hips $(8.6 \%)$.

Conclusion Adding Dega osteotomy in indicated cases of DDH, greatly helps to improve femoral head coverage and stability of the hip without adding significant complications.

Copy Right, IJAR, 2016,. All rights reserved.

\section{Introduction:-}

The primary goal in the treatment of patients with developmental dysplasia of the hip (DDH) is to obtain a stable and concentric reduction. With increasing age, treatment of DDH becomes more challenging. In older children with $\mathrm{DDH}$, pelvic osteotomies are usually required at the time of open reduction. Pelvic osteotomies improve acetabular coverage of the femoral head, and as a result of improved coverage, they improve the stability of reduction and prevent possible surgery in the future for residual acetabular dysplasia [1-2].

Various surgical techniques have been described to treat acetabular dysplasia. Although redirectional innominate osteotomies such as the Salter osteotomy reorient the hip, acetabuloplasty procedures such as the Pemberton(3), Dega (4) are felt to address both the malorientation and the hypoplasia by "reshaping" and improving the volume of the acetabulum (5).

\section{Patient and Methods:-}

Ethical permission for this study was obtained from the Zagazig University hospitals and informed consent was obtained from the guardians of all patients before participation in the study. Thirty patients were chosen from two hundred cases of developmental dysplasia of the hip presented to orthopaedic outpatient clinic of Zagazig university hospitals to be the material of this study. Eligibility criteria required Children below 8 years old with developmental 
acetabular dysplasia (acetabular index $>30^{\circ}$ ) with or without hip subluxation or frank dislocation. Patients with neuromuscular disorder, connective tissue disease or previous hip infection were excluded. Also patients under 1year or above 8 years old were excluded.

Thirty five hips in thirty patients were ultimately included in the study ( 25 unilateral and 5 bilateral). Of the 30 cases, $15(50 \%)$ were left-sided, $10(33.3 \%)$ were right sided and 5 bilateral cases. The female to male incidence ratio was 14:1. Among the studied hips 5 were subluxated (Tonnis G II), and 30 hips were dislocated (Tonnis G III and G VI).

\section{Operative Technique:-}

All cases underwent open reduction and Dega osteotomy except 2 cases in which open reduction was done in younger age. Dega osteotomy was combined with femoral osteotomy to correct the acetabular dysplasia and the femoral pathology respectively.

As regards previous management, only five hips in four cases had history of previous open reduction. From these hips only three hips in two cases required revision of the open reduction of the hip and the 2 other cases, Dega osteotomy with femoral osteotomy were only needed.

Anterior approach with 'bikini' skin incision (modified Smith-Peterson) was used in all cases. Fifteen cases required adductor tenotomy. Thirty three hips underwent femoral osteotomy either varus derotation osteotomy in 11 hips, or femoral derotation osteotomy in 22 hips. Small dynamic compression plate was used in stabilization of the femoral osteotomy in all cases.

The Dega osteotomy was performed as described by Dega in his original paper [1, 6]; all cases were operated under fluoroscopic guidance. A tricortical iliac crest graft or a fashioned graft from the femoral shortening-osteotomy was then inserted at the osteotomy site. A hip-spica cast was applied immediately after surgery for all the cases that was changed in most patients after 1.5 months. The hip was immobilized for at least 12 weeks. In bilateral cases, surgery on the second hip occurred 3-6 weeks after the first surgery.

Plain X ray anterior-posterior (AP) was made preoperatively, immediately postoperatively, after 6 weeks, at removal of the spica cast, at 6-month intervals and at the final follow up.

Computed tomographic scan (CT) was performed for all patients postoperatively to check the adequacy of the reduction within 1 week after the surgery.

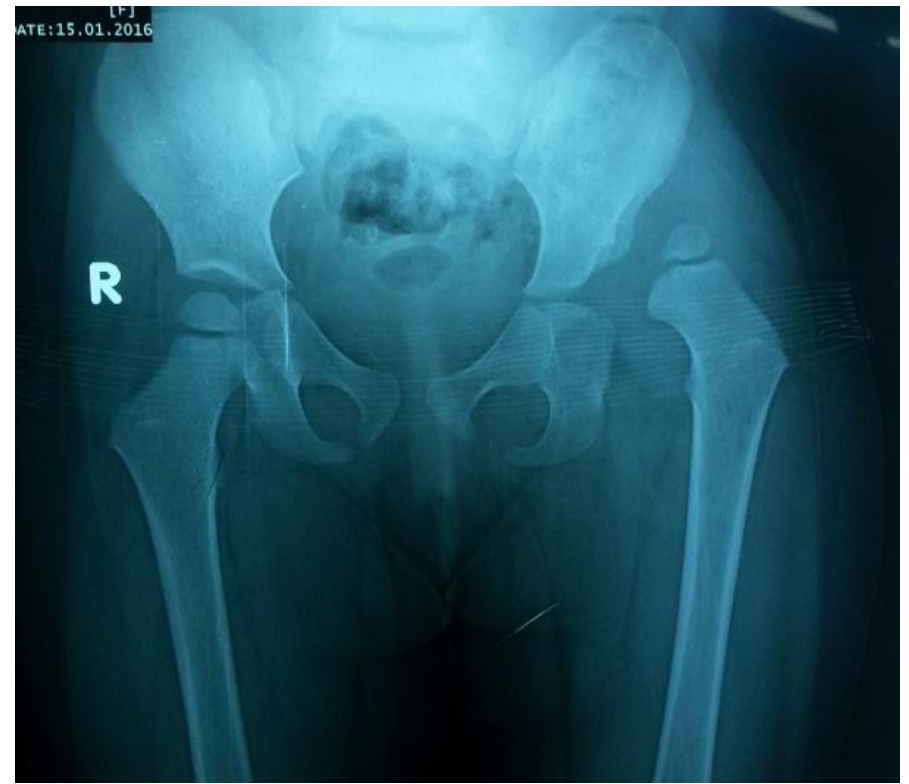

Figure 1:- Female patient 2.6ys old with pre-operative acetabular index is $50^{\circ}$ 

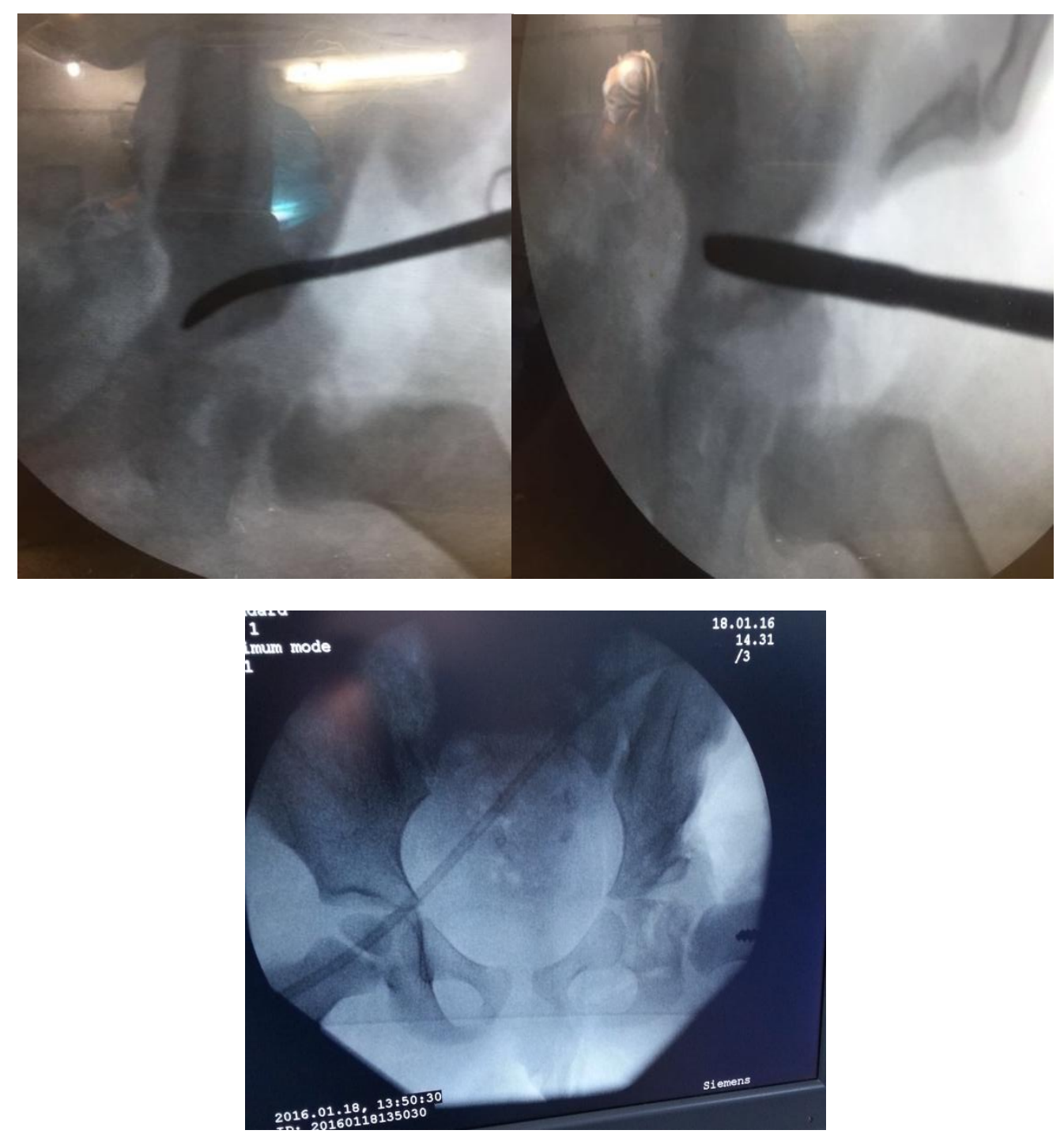

Figure 2:- Intraoperative steps of Dega osteotomy.

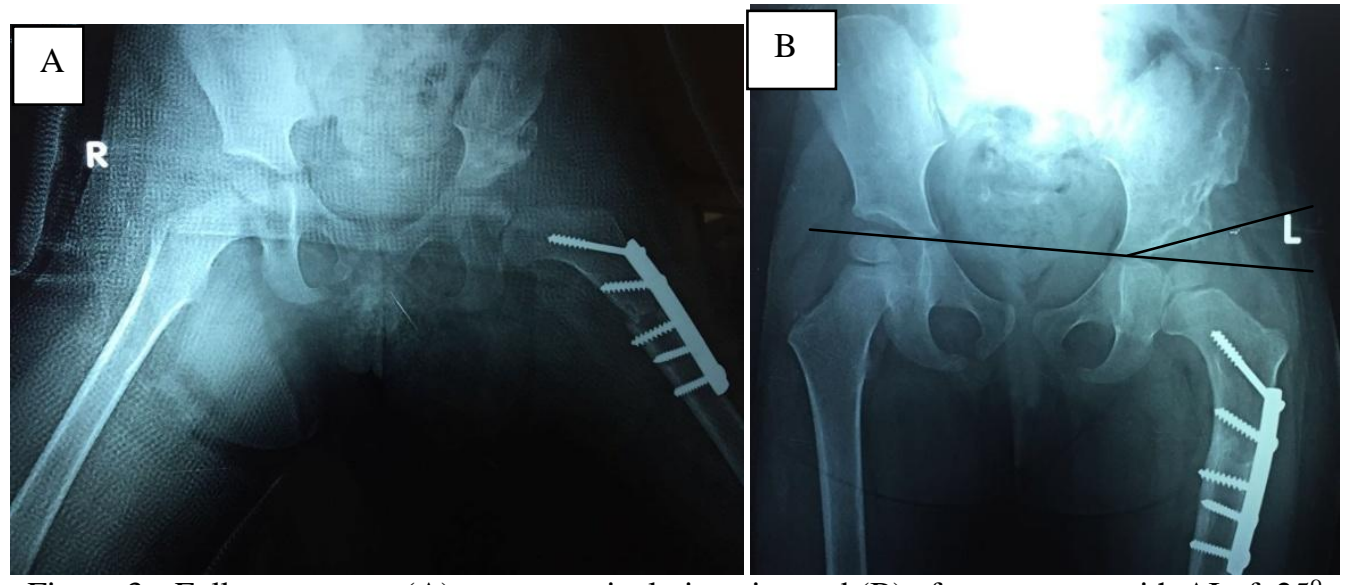

Figure 3:- Follow up x ray;(A) postoperatively in spica and (B) after one year with AI of $25^{\circ}$ 


\section{Results:-}

All patients had regular follow up for a period ranging from 12 to 24 months with a mean period of 18 months. In our study 28 patients were considered to have satisfactory results as they are either excellent or good according to modified McKay's criteria (7) and grade I or II according to Severin's radiological classification (8), and 2 patients were considered to have unsatisfactory results. According to modified Mckay criteria, 14 hips were rated excellent, 18 hips were rated to be good, 1 hip was fair and 2 hips were poor.

As regards the radiological results; preoperative acetabular indices range from 36 to 50 degrees with a mean of 45.14 degrees. At the final follow up the acetabular indices range from 15 to 30 degrees with a mean of 23.86 degrees and the mean degree of correction was 21.28 degrees. There were statistically significant decrease in the acetabular index at the final follow up compared with the preoperative index.

postoperative CE angle ranges from 16 to 40 degrees with average 29.45 degrees. Preoperatively, Shenton line was broken in all hips and postoperatively, it was intact in all hips except one hip. According to severin classification, 26 hips were GI a, 2 hips were GI b, 4 hips were GII, 2 hips were GIII and 1hip was GVI.

\section{Discussion:-}

Dega osteotomy is a type of reshaping acetabuloplasty indicated especially in hips with shallow and deficient acetabulum. There has been a lot of confusion regarding what represents a Dega osteotomy. Much of it can be attributed to Dega himself and to his coworkers $(4,6,9)$. His initial osteotomy was first briefly mentioned in a 1964 German publication (9), in this publication, Dega did not provide a detailed written description of the supraacetabular semicircular osteotomy, but he did emphasize that the medial iliac cortex was not to be cut in any area. In 1974, Dega provided an extensive written description of his incomplete transiliac osteotomy in the Polish literature. This description emphasized the importance of maintaining an intact sciatic notch hinge while simultaneously cutting the inner iliac cortex over both its anterior and its middle extent (4).

In this study there were 28 females and 2 boys (F: M ratio is 14:1) from 1.5 to 5 years old. Fifteen cases were left sided, 10 cases were right sided and 5 bilateral cases. From 35 hips only 5 hips underwent open reduction before the time they presented to us, from these 5 hips; 3 hips needed revision of open reduction. Dega osteotomy was combined with open reduction in 33 hips, and was combined with varus derotation osteotomy in 11 hips. Femoral derotation osteotomy was done with Dega osteotomy in 22 hips and only in five hips femoral shortening was added.

We could not estimate blood loss from Dega osteotomy because it is just one component of the comprehensive, complicated surgery but the total blood loss from the surgery ranged from 150-250 ml.

In this study, we documented excellent \& good clinical and radiographic results (32 hips from 35 hips), comparable with those reported by Grudziak and his colleagues (10).

In this study we found that Dega osteotomy greatly improve the femoral head coverage and increase the hip joint stability. There are published case series that report improvement in AI with Dega acetabuloplasty. In one of the largest series of 70 hips, Reichel and Hein [11] reported an 18 degrees improvement. In 24 hips, Grudziak and Ward [12] reported an improvement from 33 preoperatively to 12 at follow up, and Karlen et al. [13] from 37 to 13 in 26 hips. In a more recent report, Al-Ghamdi et al. [14] reported an average 18 degrees improvement in 21 hips over 87 months of average follow-up. Also Aksoy and his colleagues (15) reported improvement of AI from average of 35 degrees to average of 13 degrees. Our results are comparable with these published series with an improvement from 44.8 preoperatively to 23.8 degrees at final follow up.

In this study, the CEA was improved in all cases with a mean final follow-up CEA of $29.45^{\circ}$. This was similar to the results obtained by Karlen et al (13) who obtained a good outcome in 24 of 26 patients, with a postoperative average of $29^{\circ}$. Reichel and Hein (11) obtained an improvement of the CEA at the final follow up with a mean of $22.1^{\circ}$. AlGhamdi and colleagues (14) reported improvement in the final follow up CEA with a mean of $25^{\circ}$.

In this study, there was a reverse correlation between the age and the results. The younger the child, the better the results. These results are similar to those obtained by previous series done by Otaify AE (16) and Issin et al. (17) 
they believe that the results of treatment of DDH are largely dependent on the age of the child in which the treatment is undertaken.

According to Albinana and colleagues [18], acetabular dysplasia is directly related to the age at open reduction, increasing from $20 \%$ at 6 months to $60 \%$ at 32 months or older. Hence, for these authors, children treated at 18 months of age have a probability of $36 \%$ to develop acetabular dysplasia. So in patients above 18 months, acetabuloplasty is indicated if the acetabulum is deficient in 3D CT with high AI and also according to Herring (19) if more than one third of the femoral head is uncovered intraoperative after open reduction with the hip is placed in extension and neutral rotation and abduction.

One of the important technical points is to put the bone graft for Dega osteotomy opposite the cortical iliac bone not the cancellous to prevent graft impaction against the cancellous bone and loss of some degrees of AI correction.

\section{Complications:-}

Avascular Necrosis (AVN) is a major cause of long-term disability after the treatment of DDH. It is a problem directly associated with the treatment. Wide range of AVN in many studies are present from 5\% to $40 \%$ or more. Hess and colleagues (20) reported 6\% AVN incidence, Elsayed and colleagues (21) reported 13.7\% AVN rate and Akgul and colleagues (24) repoted 27.2\% incidence of AVN. In our study Only 6 hips (17.1\%) have AVN. Three hips were grade 1 according to Bucholz- Ogden classification and healed without significant deformity. Avascular necrosis was attributed in our cases to prolonged operative time, older child and also was more in revision cases. It is reported that vascular changes may not be evident until 6-11 years after the reduction (22). In this regard, any study along with ours with a shorter follow-up may not be conclusive about avascular necrosis.

Carsi and Clarke (23) asked if incomplete periacetabular acetabuloplasty, as an added step to delayed open reduction, (1) diminish the risk of developing acetabular dysplasia; or (2) increase the rate of AVN compared with patients treated with open reduction alone? And they found that; the addition of an incomplete periacetabular acetabuloplasty to all hips undergoing intentionally delayed open reduction eliminated residual acetabular dysplasia, whereas it did not appear to have deleterious effects, as evidenced by an equal AVN proportion and similar Severin and Mckay scores.

In our study we have 2 cases of periprothetic femoral fracture that required removal of the plate and open reduction of the femoral fracture and fixation by 8 holes small DCP.

We reported one case of anterior dislocation in our study that requires revision of open reduction and revision of the femoral osteotomy.

\section{References:-}

1. Dega W. Significance of surgical methods and techniques for the results of treatment in congenital hip dislocation (critical evaluation of methods applied). Chir Narzadow Ruchu Ortop Pol 1969; 34:179-189.Jh

2. Salter RB, Dubos JP. The first fifteen years' personal experience with innominate osteotomy in the treatment of congenital dislocation andsubluxation of the hip. Clin Orthop 1974; 98:72-103.

3. Pemberton PA. Pericapsular osteotomy of the ilium for treatment of congenital subluxation and dislocation of the hip. J Bone Joint Surg Am. 1965;47:65-86.

4. Dega W. Transiliac osteotomy in the treatment of congenital hip dysplasia. Chir Narzadow Ruchu Ortop Pol. 1974; 39: 601-613.

5. Chung CY, Choi IH, Cho TJ, et al. Morphometric changes in the acetabulum after Dega osteotomy in patients with cerebral palsy.J Bone Joint Surg Br. 2008;90-1:88-91.

6. Dega W. Selection of surgical methods in the treatment of congenital dislocation of the hip in children (in Polish). Chir Narzadow Ruchu Ortop Pol 1969; 34:357-366.

7. McKay DW. Comparison of the innominate and pericapsular osteotomy in the treatment of congenital dislocation of the hip. Clin Orthop 1974;98:124

8. Severin E. Contribution to the knowledge of congenital dislocation of the hip joint. Acta Chir Scand Suppl 1941; 84:1.

9. Dega W. Schwierigkeiten in der chirurgischen reposition derveralteten kongenitalen subluxation des hüftgelenkes bei Kindern. Beitr Orthop Traumatol. 1964;11:642-7. 
10. Grudziak JS, Labaziewicz L, Kruczynski J, Nowakowski A, Wierusz-Kozlowska M, Schwartz R. Combined one-staged open reduction, femoral osteotomy, and Dega pelvic osteotomy for developmental dysplasia of the hip. J Pediatr Orthop.1993;13:680.

11. Reichel H, Hein W. Dega acetabuloplasty combined with intertrochanteric osteotomies. Clin Orthop Relat Res 1996; 323:234-242.

12. Grudziak JS, Ward WT. Dega osteotomy for the treatment of congenital dysplasia of the hip. J Bone Joint Surg Am 2001; 83-A:845-854.

13. Karlen JW, Skaggs DL, Ramachandran M, Kay RM. The dega osteotomy: a versatile osteotomy in the treatment of developmental and neuromuscular hip pathology. J Pediatr Orthop 2009; 29:676-682.

14. Al-Ghamdi A, Rendon JS, Al-Faya F, Saran N, Benaroch T, Hamdy RC. Dega osteotomy for the correction of acetabular dysplasia of the hip: a radiographic review of 21 cases. J Pediatr Orthop 2012; 32: 113-120

15. Aksoy C, Yilgor C, Demirkiran G and Caglar O. Evaluation of acetabular development after Dega acetabuloplasty in developmental dysplasia of the hip. Journal of Pediatric Orthopaedics B 2013, 22:91-95.

16. Otaify AE. One-stage surgery for developmental dysplasia of the hip in older children. Pan Arab J Orth Trauma 2002; 6(1): 49-61.

17. Issın A, Öner A, Koçkara N and Çamurcu Y. Comparison of open reduction alone and open reduction plus Dega osteotomy in developmental dysplasia of the hip. Journal of Pediatric Orthopaedics B 2016, 25:1-6.

18. Albinana J, Dolan LA, Spratt KF, Morcuende J, Meyer MD, Weinstein SL. Acetabular dysplasia after treatment for developmental dysplasia of the hip. Implications for secondary procedures. J Bone Joint Surg Br. 2004;86:876_886.

19. Herring JA. Developmental dysplasia of the hip. Tachdjans pediatric orthopaedics 2008; 4th edition; 16: 637756.

20. Hess T, Esser O, Mittelmeier H. Combined acetabuloplasty and varus derotation osteotomy in congenital dislocation of the hip. International Orthopaedics (SICOT) (1996) 20: 350 - 356.

21. El-Sayed M, Hegazy M, Abdelatif M N, ElGebeily A M, ElSobky T Nader S. Dega osteotomy for the management of developmental dysplasia of the hip in children aged 2-8 years: results of 58 consecutive osteotomies after 13-25 years of follow-up. J Child Orthop (2015) 9:191-198.

22. Kim HW, Morcuende JA, Dolan LA, Weinstein SL. Acetabular development in developmental dysplasia of the hip complicated by lateral growth disturbance of the capital femoral epiphysis. J Bone Joint Surg Am 2000; 82A:1692-1700.

23. Carsi M B and Clarke N M P. Acetabuloplasties at Open Reduction Prevent Acetabular Dysplasia in Intentionally Delayed Developmental Dysplasia of the Hip: A Case-control Study. Clin Orthop Relat Res 2016; 474(5): 1180-1188. 